\title{
HEURISTIC COMPARATIVE ASSESSMENT OF NON-CONVENTIONAL WAREHOUSE DESIGNS
}

\author{
Antonio T. ESMERO QUEenIE Rose S. BRANZUELA \\ JESSILYN T. PAYPA SHARMAINE MYKa S. ROJO ${ }^{\circledR}$ \\ EduARdo S. SACAY JR. EgBerto F. SElERIO JR. \\ LANNDON A. OCAMPO
}

Lanndon A. Ocampo

Cebu Technological University, Philippines ORCID 0000-0002-5050-7606

Corresponding author: e-mail: lanndonocampo@gmail.com

Antonio T. Esmero

University of San Jose-Recoletos, Philippines ORCID 0000-0003-4702-4512

Queenie Rose S. Branzuela University of San Jose-Recoletos, Philippines

ORCID 0000-0001-8540-7093

\section{A B S T R A C T}

In the unit-load warehouse (UW) design, the aisle design problem dealing with storage space layout is the first among the three main problems. Several conventional and non-conventional designs have been proposed in the literature. In general, the assessment of UW designs is commonly carried out using analytical approaches. However, such an approach may be inadequate due to assumptions or approximations, making results unrealistic. Aiming to bridge this gap, this research develops an assessment framework that employs the FlexSim software for simulating the conventional, Flying- $V$ and Fishbone designs based on a real case from a Philippine manufacturing company. Using a computer simulation, this research investigates factors not yet tractable with present analytical methods. The factors employed for the comparative assessment are "picking run-time", "travel distance", and "capacity". The results suggest that the Fishbone design provides the most advantage compared to the Flying-V and other conventional designs. With the proposed Fishbone design, the company is expected to save, on average, $52.39 \%$ of picking run-time, $32.25 \%$ travel distance, and increase storage capacity by $7.5 \%$. The research findings are compared to previous studies based on analytical approaches.
Jessilyn T. Paypa University of San Jose-Recoletos, Philippines

ORCID 0000-0002-7988-8529

Sharmaine Myka S. Rojo University of San Jose-Recoletos, Philippines

ORCID 0000-0003-3427-2445

Eduardo S. Sacay Jr. University of San Jose-Recoletos, Philippines

ORCID 0000-0002-6415-7846

Egberto F. Selerio Jr Cebu Technological University, Philippines ORCID 0000-0002-7326-3819

\section{INTRODUCTION}

Several component subsystems exist in distribution centres (DCs), which are typically categorised based on processes. These subsystems include receiving, storage, order picking, and shipping. The pallet storage area is the most common building block of these systems. It consists of storage racks, aisles between them, and one or more pickup and deposit (P\&D) points (Gue \& Meller, 2009), commonly called a "warehouse". Most space in a DC is usually allocated

Esmero, A. T., Branzuela, Q. R. S., Paypa, J. T., Rojo, S. M. S., Sacay, E. Jr. S., Selerio Jr., E. F., \& Ocampo, L. A. (2021). Heuristic comparative assessment of non-conventional warehouse designs. Engineering Management in Production and Services, 13(1), 89-103. doi: 10.2478/emj-2021-0007 
for the warehouse. Almost all products are received and stored in pallet quantities in this area. Warehousing does not necessarily add value to the product; however, it is undoubtedly essential in operations (Feng et al., 2018), which in recent years has drawn research interest to the topic, especially in logistics research.

Unit-load warehouse (UW) designs were among the highly explored logistics research topics (Feng et al., 2018). UWs are used to store items - typically, pallets - that can be stowed or retrieved in a single trip and usually handle standardised cargo types. According to Gue and Meller (2009), UWs are used in at least two ways in a DC: (1) as areas for order picking, where products are often received and shipped in pallet quantities (e.g., distributors of groceries or appliances), and (2) as areas reserved to replenish fast-pick areas. UW designs take account of the general type of warehouse operations (e.g., singlecommand, dual-command), the number and location of the P\&D points, and several aisle characteristics (Masae et al., 2020a).

The current literature discusses three primary UW design variants: conventional, non-conventional, and general warehouses. Among the three variants, the conventional and non-conventional designs were commonly employed in UWs (e.g., Gue \& Meller, 2009; Meller \& Gue, 2009; Feng et al., 2018), which is central to this study. As expounded by Masae et al. (2020a), conventional warehouses have "rectangular shape with parallel picking aisles that are perpendicular to a certain number of straight cross-aisles" (Fig. 1 , left). Subsequently, warehouses with more than two cross-aisles are often referred to as multi-block warehouses, where each block in the warehouse consists of several sub-aisles (Fig. 1, right) (Masae et al., 2020a).

In a conventional warehouse, storage racks are arranged to create parallel picking aisles, perhaps with one or more cross-aisles, to allow workers to move quickly between picking aisles. This structure forces workers to travel rectilinear distances (i.e., north-south and east-west) to picking locations. On the other hand, non-conventional warehouses do not arrange all picking aisles or cross-aisles parallel to each other but "select a different layout to facilitate reaching certain regions of the warehouse or to improve space utilization" (Masae et al., 2020a).

While the conventional design is popular in the industry, several inadequacies were highlighted. For instance, in a conventional warehouse, it is always necessary to traverse the full rectilinear distance in a picking command (Cardona et al., 2012). Generally, it tends to limit productivity in a single-command UW (Gue \& Meller, 2009; Meller \& Gue, 2009; Cardona et al., 2012; Clark \& Meller, 2013; Feng et al., 2018). This contention leads to the question of how to arrange cross-aisles and picking aisles to minimise the expected distance to pick in a single-command unit-load warehouse (Gue \& Meller, 2009). To answer this question, non-conventional designs were developed. The literature presents six non-conventional UW designs, namely the U-shaped, Chevron, Leaf, Butterfly, Fishbone, and Flying-V designs (e.g., Glock \& Grosse, 2012; Venkitasubramony \& Adil, 2016; Feng et al., 2018; Masae et al., 2019; Masae et al., 2020a; Masae et al., 2020b). These designs present a noticeable reduction in expected single-command distance (Öztürkoğlu et al., 2012; Öztürkoğlu, 2016).

The U-shaped layout consists of a central aisle arranged in the form of a " $U$ ". It is also composed of various picking aisles extending from the central aisle. The problem of this design lies primarily in its narrow aisles, which restrict the mobility of picking devices aside from restricting traffic in its central aisle (Masae et al., 2020a), which may not be suitable in some UWs. On the other hand, the Chevron, Leaf, and Butterfly designs are similar to the Fishbone design (Öztürkoğlu et al., 2012). As a consequence of their insignificant difference, Öztürkoğlu et al. (2012) claimed that similar benefits to the Fishbone design could be expected under turnover-based storage.

The Flying- $\mathrm{V}$ design challenges the first design assumption of the conventional design, which presumes that cross-aisles are straight and meet picking aisles only at right angles. In this design, a cross-aisle is inserted into the storage space and does not constrain it to meet the picking aisles only at right angles (Fig. 2). On the other hand, the Fishbone design challenges the second design assumption of conventional warehouses, which presumes that picking aisles must be parallel to one another (Fig. 3). These two UW designs - the Flying-V and Fishbone designs - are the most widely studied UW designs in the literature (Masae et al., 2020a). Based on the previous discussions, this study focuses on the Flying- $\mathrm{V}$ and Fishbone designs.

Although the Flying- $\mathrm{V}$ and the Fishbone design both utilise a V-shaped cross-aisle, they are relatively different in other aspects. For instance, the proponents of the two designs (Gue \& Meller, 2009) recognised that "travel in a Fishbone warehouse is much simpler than travel in a Flying-V warehouse". For this reason, comparative assessments were commonly employed in previous literature to identify which 


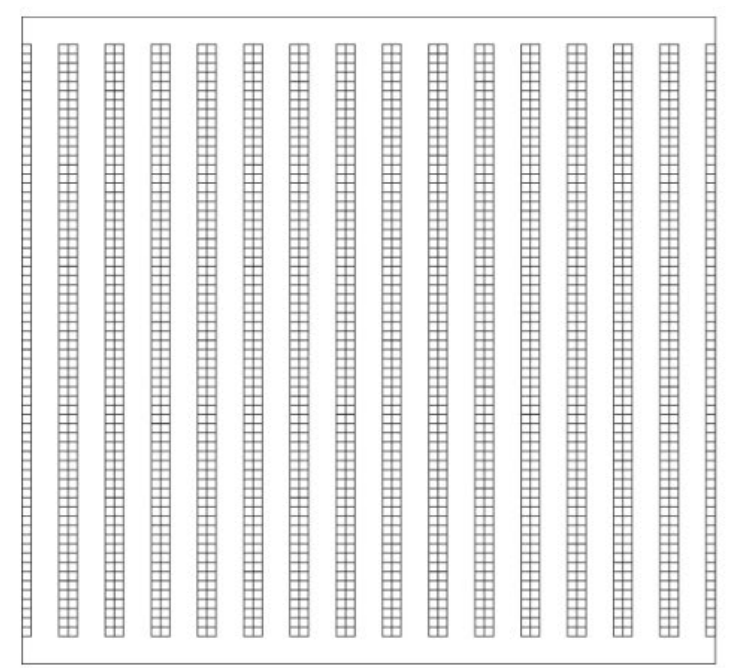

Fig. 1. Conventional design

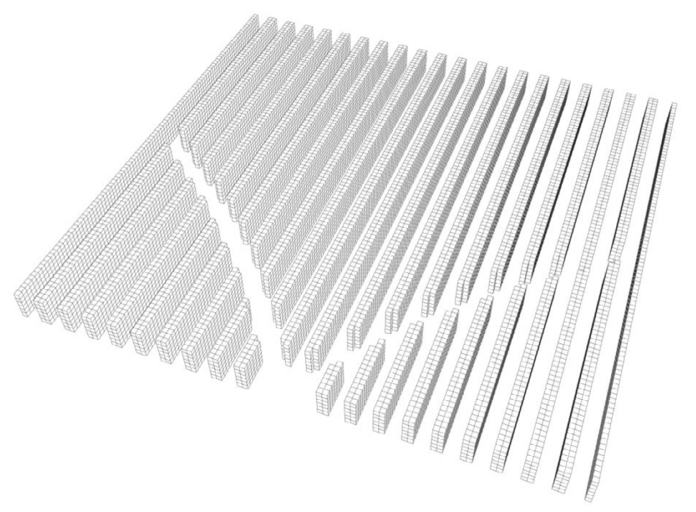

Fig. 2. 3D Flying-V design

among the two prominent UW designs possess more utility (Pohl et al., 2011; Gue et al., 2012; Clark \& Meller, 2013; Masae et al., 2020a). Based on analytical approaches employed in the literature, the Fishbone design is collectively considered more superior than the Flying- $\mathrm{V}$ design.

While the literature offers several analytical studies on Flying-V and Fishbone designs, their comparative assessment in a real case environment is relatively unexplored. Furthermore, UW design primarily aims to maximise picking efficiency, one of the key performance indicators for measuring the flow of goods in warehouses is the picking run-time, which is highlighted as among most critical metrics for warehouse managers in the WERC (Warehousing Education and Research Council) survey (Öztürkoğlu \& Hoser, 2019). Counterintuitively, the current literature contains no attempts to consider picking run-time in evaluating UW designs. This gap may be consequent to the limitations of analytical approaches.
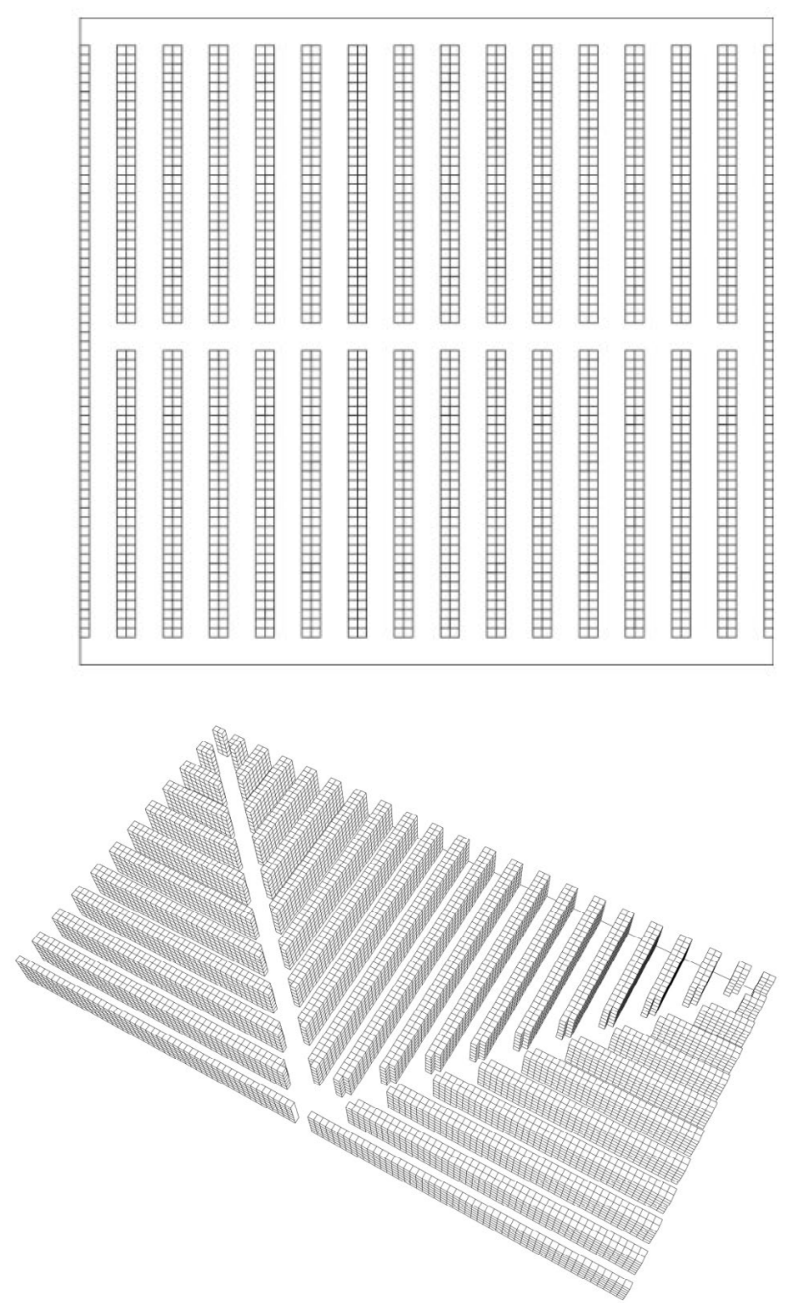

Fig. 3. 3D Fishbone design

Usually, to treat a problem analytically (i.e., considering an analytical approach is possible), one needs to resort to some assumption or approximation, e.g., an assumption that pickers are equally efficient in traversing through different UW designs with equal travel distances; hence, equal picking run-time. However, real-life situations are more complicated. For instance, an increase in the number of turns required to traverse through aisles in a UW design would increase travel time due to slowing down due to turns. However, this factor is avoided by analytical approaches through assumptions or approximations together with several other factors (e.g., randomness, asymmetry). Thus, employing other methods that allow studying factors not yet tractable with analytical methods is warranted for evaluating UW designs.

To bridge the gaps, this research employs a heuristic approach aided by the FlexSim software package in the comparative assessment of the conventional, Flying-V, and Fishbone design. The assessment is 
made in a real-case environment in a Philippine manufacturing company as part of a UW design improvement project. This study aims to provide a mix of theoretical and pragmatic perspectives in UW design. The novelty of this paper is three-fold. First, it pioneers the proposal of an easy-to-adopt approach to UW design for industry practitioners. Second, it is the first to employ the integration of picking run-time, travel distance, and capacity as performance assessment metrics for UW design. Lastly, it is among the first to illustrate an assessment of conventional and non-conventional (e.g., Flying- $\mathrm{V}$ and Fishbone) UW designs in a real case scenario, verifying the findings of previous studies employing analytical methods.

\section{LITERATURE REVIEW}

\subsection{WAREHOUSE AISLE DESIGN PROBLEM}

Warehouse design is complicated because many interrelated design problems lead to many potential designs (Pohl et al., 2009a). There are three main problems in warehouse design. The first is the aisle design problem, which deals with the layout of storage space. The second is product allocation, which tries to find the right positioning of products in the storage space. The third is the order picker routing problem, which determines the best sequence of locations for a worker to visit when building orders. The first problem - the aisle design problem - is the primary concern of this paper. The following discussions elucidate the evolution of studies dealing with the aisle design problem.

Space is the primary concern in warehouse aisle design because its main objective is to store stocks. Moder and Thornton (1965) explored how floor space utilisation is affected by some dependent and independent variables. Among the independent variables affecting floor space is the "slant angle of the pallets". Their study proposed a mathematical model for assessing the extent that floor space change concerning the angle of placement of the pallets and aisle width. More recent studies on modelling warehouse aisle designs have been grounded on the idea proposed by Moder and Thornton (1965) (Öztürkoğlu, 2016; Kocaman et al., 2021; Öztürkoğlu \& Hoser, 2019).

Following the work by Moder and Thornton (1965), Francis (1967a, 1967b) investigated the shape of optimal warehouse designs considering a single dock with rectilinear travel between the storage space and the dock. Elements of warehouse layout, such as space utilisation and travelling cost of a handling unit, were investigated by Berry (1968), who proposed two types of UW design from his findings. As pointed out by Öztürkoğlu et al. (2012), the first design assumed "rectangular pallet blocks with the same depth arranged around a main orthogonal gangway". On the other hand, the second layout assumed that "floor stored pallets were arranged in different depths around a single diagonal gangway providing access to all stacks" (Öztürkoğlu et al., 2012).

Building on the ideas previously discussed, Pohl et al. (2009b) showed that the optimal placement of a "middle" cross-aisle in conventional rectilinear designs should be slightly behind the middle. Crossaisles are appropriate for order picking operations, in which more than one location is visited per trip but may not be applicable in single-command operations (Öztürkoğlu et al., 2012), which is an idea considered in this study. In conventional designs, workers travel rectilinear paths to store and receive pallets. However, this design generally limits the productivity of operations. For instance, the conventional design is based on several undocumented and unnecessary assumptions. Why, for instance, must cross-aisles meet picking aisles at right angles? Or why do picking aisles have to be parallel? The answer, of course, is that they do not, and various works have shown that adhering to these haphazard assumptions, which, by the way, is the most commonly adopted practice in the industry, could result in a significant penalty in labour costs (Gue \& Meller, 2009; Pohl et al., 2011; Gue et al., 2012; Clark \& Meller, 2013; Masae et al., 2020a).

To address this problem with the conventional design, "radial aisles" were proposed in previous studies. White (1972) showed that "radial aisles" reduced travel distance in a non-rectangular UW design. With the assumption of continuous warehouse space, he proved that travel distance from the P\&D point to any point in the storage area was close to the Euclidean distance when the number of radial aisles increased. Gue and Meller (2009) extended this idea to propose two non-conditional designs to reduce single-command travel under a random storage policy, namely the Flying- $\mathrm{V}$ and Fishbone designs. The following discussions present the related literature that expounds on the Flying-V and Fishbone designs.

\subsection{FLYING-V DESIGN}

In the Flying-V, picking aisles are parallel with orthogonal cross-aisles at the warehouse's top and 
bottom (Pohl et al., 2011). According to Gue and Meller (2009), for reasonable values of cross-aisle width, the optimal shape of the cross-aisle is $\mathrm{V}$-shaped, with the vertex at the $\mathrm{P} \& \mathrm{D}$ point. The Flying-V aisle appears to be curved, but the cross-aisle segments between picking aisles are piecewise linear (Pohl et al., 2011).

The assessment of Gue and Meller (2009) on the Flying-V design yielded a $10 \%$ improvement in single-command travel under a random storage policy when compared to an equivalently sized conventional design with no middle cross-aisle. Under the same conditions, Feng et al. (2018) made a comparison of the Flying- $\mathrm{V}$ to the conventional design using optimal locations for $\mathrm{P} \& \mathrm{D}$ points determined by an optimal integer programming model. The results of their analytical evaluations show that the Flying- $\mathrm{V}$ design can obtain $8-18 \%$ distance savings compared to the conventional design (Feng et al., 2018).

Öztürkoğlu (2016) investigated the effects of various $\mathrm{P} \& \mathrm{D}$ points on both the capacity and the travel distance of non-conventional warehouses, including the Flying- $\mathrm{V}$ design. Their results revealed that the Flying-V design, in general, requires $61.17 \%$ less space than the improved designs in the study. They also found out that as the number of $P \& D$ points increases (greater than 11), the Flying- $\mathrm{V}$ design "overwhelms the improved designs because it requires less additional space" (Öztürkoğlu, 2016). Clark and Meller (2013) developed a three-dimensional model, which confirmed that "the Flying- $\mathrm{V}$ design is advantageous to implement over the standard (conventional) warehouse configuration".

\subsection{FISHBONE DESIGN}

The Fishbone design has orthogonal cross-aisles at the top, left, and right edges of the warehouse (Pohl et al., 2011). The middle cross-aisle is diagonal and straight, with vertical picking aisles above and horizontal picking aisles below. The middle cross-aisle slope is calculated by minimising the $\mathrm{P} \& \mathrm{D}$ distance to a single random location in the warehouse. The assessment of Pohl et al. (2009a) revealed that, under a random storage policy, the Fishbone design reduces single-command travel by up to $20 \%$ and dual-command travel by $10-15 \%$ when compared to the conventional design.

Pohl et al. (2009b) explored the Fishbone design for task interleaving operations. Their analytical evaluations showed that the Fishbone designs offer a decrease in expected travel distance over several conventional conditional designs. The underlying notion is that a cross-aisle that cuts diagonally across the picking aisles affords "Euclidean efficiencies" (Gue \& Meller, 2009; Cardona et al., 2012), which allows workers to get to most picking locations. In an analytical assessment performed by Clark and Meller (2013) on the robustness of non-conventional designs in terms of vertical travel, it was shown that, while their per cent improvement generally diminishes as the height of the rack increases, the Fishbone design maintains a greater per cent improvement over the Flying-V design. Its design, considering vertical travel, was then later formalised by Cardona et al. (2015).

Dukic and Opetuk (2012) and Çelik and Süral (2014) performed an evaluation of the Fishbone design for order-picking systems while considering different routing policies. Their analytic approaches discovered that the Fishbone design could perform as much as around $30 \%$ worse than an equivalent conventional design under a random storage policy and steady demand. They also found that depending on how skewed the demand is, the Fishbone design can outperform the conventional design for dedicated storage with non-uniform demand.

\subsection{SyNTHESIS OF THE REVIEW AND RESEARCH GAPS}

While the Flying- $\mathrm{V}$ design shows an advantage over the conventional design, that advantage diminishes as the number of levels in a warehouse increases (Clark \& Meller, 2013). Thus, if the warehouse is large enough, then the Flying- $\mathrm{V}$ design is a better choice. However, if the warehouse is small, the conventional design is more suitable. Also, provided that the number of $P \& D$ points is fixed, and their positions are optimal, the Flying- $\mathrm{V}$ design seems to sacrifice some space to achieve the distance saving goal (Feng et al., 2018). Much like the Flying- $\mathrm{V}$ design, in gaining an advantage in terms of travel distance, the Fishbone design requires approx. 5\% more space (Pohl et al., 2009b).

While these inadequacies may draw interest from an academic perspective, in most industries, the luxury of space may not be as abundant as analytical approaches, implicitly suggested via assumptions. In a fixed-space layout, the contention now turns to whether the Flying- $\mathrm{V}$ and Fishbone designs are still capable of outperforming the conventional design in terms of crucial indicators, such as picking run-time, travel distance, and capacity. Note that while picking 
run-time has been recognised as a vital performance indicator of UW design (Öztürkoğlu, 2016), it is not yet used in the assessment.

These contentions on the Flying- $\mathrm{V}$ and Fishbone designs warrant further investigation, especially in areas unexplored in the current literature. For instance, in assessing both the Flying- $\mathrm{V}$ and Fishbone designs, analytical approaches are commonly utilised (e.g., analytical experiments). For a study aimed at warehouse designers in practice, this approach might be insufficient. Real case applications are seldom employed in recent literature. Furthermore, the trend of employing analytical approaches for assessing UW designs has somehow led the current literature to disregard the provision of friendly approaches for warehousing practitioners in the industry to replicate assessment procedures. Analytical approaches also tend to oversimplify the complex nature of UW designs, often avoiding several design complexity factors, e.g., slow-down at turning points, which has dire effects on picking run-time - the completion time of a picking routine. These factors indicate that travel speed is not constant at all points of the layout. It varies especially at the turning points because the picker's rotational motion reduces vehicle speed (e.g., forklift speed). This explanation indicates that UW designs may have the same total travel distance yet different picking run-time. Several other factors may affect picking run-time, e.g., randomness, aisle width, and layout asymmetry. These factors are challenging to integrate into an analytic model, which explains why most models impose assumptions to avoid them.

\subsection{FlexSim Simulation SOFTWARE}

Computer-simulation methods are by now an established tool in many branches of science. The motivations for computer simulations of physical systems are manifold. One of the main motivations is the elimination of assumptions and approximations. With a computer simulation, analysts can study systems not yet tractable with analytical methods. The computer simulation approach allows studying complex systems and gaining insights into their behaviour. Complexity, which is persistent in real-world applications, can go far beyond the present analytic methods. Since they can be used to study complex systems, computer-simulation methods provide standards against which approximate theories, e.g., analytical evaluations, may be compared.

FlexSim software integrates virtual reality technology and discrete object-oriented simulation. At present, the FlexSim simulation is primarily used in logistics, warehouse optimisation and design, and the optimisation of production lines (Tang et al., 2013; Liu et al., 2016; Kęsek et al., 2018). The applications of virtual reality technology and object-oriented simulation technology in assessing UW designs are unexplored. Thus, there is a need to explore the use of computer simulation to study UW designs' efficiency and compare results with analytic approaches employed in the literature. To address the gaps mentioned in this section, this study developed an assessment framework that utilises the FlexSim software for simulating the conventional, Flying- $\mathrm{V}$, and Fishbone designs based on a real case from a Philippine manufacturing company. The performance indicators used for the comparative assessment are "picking runtime", "travel distance", and "capacity." The methodology used in this study is illustrated in the following section.

\section{Methodology}

This study employs a quantitative approach in assessing the performance of conventional, Flying- $\mathrm{V}$, and Fishbone designs. Since the available analytical approaches in the literature seem incapable of assessing the indicator 'picking run-time' to evaluate this performance indicator, a simulation-based approach is adopted in this study, using the FlexSim software package as the main instrument. FlexSim is a widely adopted warehouse layout model simulation software in practice and is broadly discussed in the current literature (Huihui et al., 2016; Yafei et al., 2018), which allows designing, testing, and redesigning the layout of the warehouse ahead of commissioning projects and without risk to on-going operations. In this simulation, single-command operation and random picking are assumed. The detailed procedure adopted in this work is as follows:

Step 1. (Develop the warehouse blueprint) Measure the dimensions of the warehouse and develop a blueprint.

Step 2. (Estimate relevant parameters) Based on the developed warehouse blueprint, determine the relevant parameters for the simulation. This study adopted the standard geometry of the V-shaped nonconventional UW design introduced by Öztürkoğlu (2016), as illustrated in Fig. 4. The description of the parameters and features is presented in Table 1.

The required computations for each feature are distinct for the Flying-V and Fishbone designs. The 


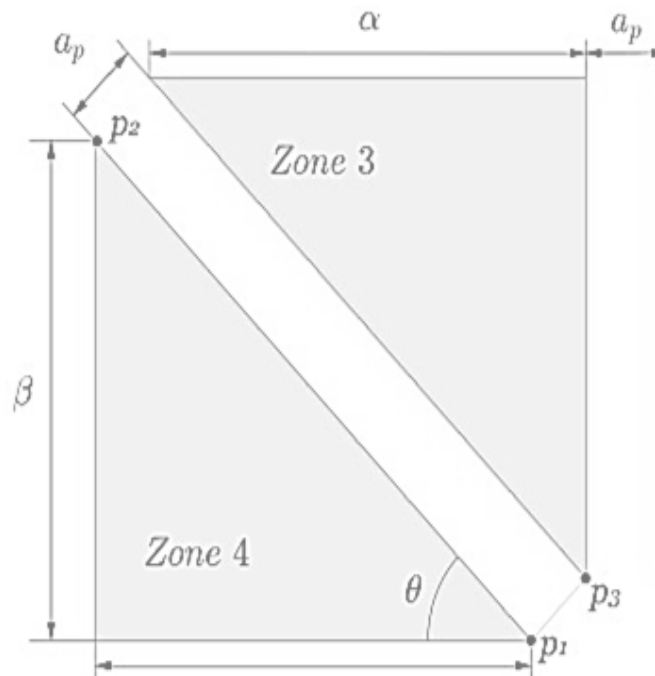

$\alpha$

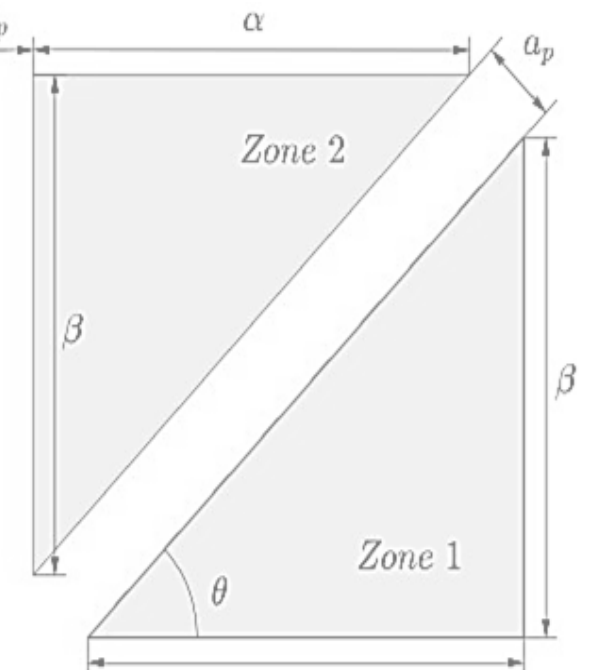

$\alpha$

Fig. 4. Standard geometry of V-shaped non-conventional UW designs Source: (Öztürkoğlu, 2016)

diagonal aisle slope for the Flying- $\mathrm{V}$ and the Fishbone designs is illustrated in Equation (1) and Equation (2), respectively. The diagonal aisle angle is obtained using Equation (3) for both Flying-V and Fishbone designs. The length of the triangle's height is obtained for the Flying- $\mathrm{V}$ and Fishbone designs using Equation (4) and Equation (5), respectively. The length of the triangle base is calculated using Equation (6) and Equation (7) for the Flying-V and Fishbone designs, respectively. Lastly, the warehouse area for both Flying- $\mathrm{V}$ and Fishbone designs is determined using Equation (8).

Tab. 1. Description of the variables

\begin{tabular}{|c|l|}
\hline PARAMETERS & \multicolumn{1}{c|}{ DescriPtion } \\
\hline$e_{w}, e_{l}, e_{h}$ & Dimensions of the openings \\
\hline$a_{1}$ & Horizontal stacking space \\
\hline$a_{2}$ & Vertical stacking space \\
\hline$a_{3}$ & $\begin{array}{l}\text { GMP space requirement from the pallet to } \\
\text { the wall }\end{array}$ \\
\hline$a_{p}$ & Aisle width \\
\hline FEATURES & \\
\hline$m$ & The slope of the diagonal aisle \\
\hline$\theta$ & The angle of the diagonal aisle \\
\hline$\beta$ & The length of the height of the triangle \\
\hline$\alpha$ & The length of the base of the triangle \\
\hline$A$ & The width of the warehouse \\
\hline$B$ & The length of the warehouse \\
\hline
\end{tabular}

$$
\begin{gathered}
m_{\text {flying }-V}=\frac{e_{l}+a_{p}+2 a_{2}}{7\left(e_{w}+a_{1}\right)} \\
m_{\text {fishbone }}=\frac{e_{l}+a_{p}}{4\left(e_{w}+a_{1}\right)} \\
\theta=\tan ^{-1}(m) \\
\beta_{\text {flying-V }}=u+8 e_{w}+7 a_{1}+2 \\
\beta_{\text {fishbone }}=u+4 e_{l}+a_{1}+2 a_{p}+1 \\
\alpha_{\text {flyng-V }}=3 a_{p}+5 a_{2}+2 a_{2}+a_{c} \\
\alpha_{\text {fishbone }}=a_{3}+10 e_{w}+9 a_{1}+3.25 \\
\text { Area }=(A B \mid A=2 \alpha, B=\beta)
\end{gathered}
$$

Step 3. (Set-up the simulation conditions) Using the FlexSim software, the simulation was executed using the following conditions: each palletised unit weighs 1000 kilograms, the average moving speed of the forklift is 5 metres per second, its average lifting speed is 0.45 metres per second, and the items in the warehouse are randomly picked. The blueprint, along with the computed variables, is recorded into the FlexSim with the pre-determined conditions.

Step 4. (Run the simulation) The simulation was run for a different number of random picks, $\delta=$ $(30,80) \in \mathbb{Z}^{+}$, for the conventional, Flying- $\mathrm{V}$, and Fishbone designs. The performance indicators measured in this simulation are 'picking run-time,' 'travel distance,' and 'capacity.' In visualising the flow of this heuristics approach, a Heuristic Comparative Assessment of the UW Designs (HCAUD) framework is presented in Fig. 5. 


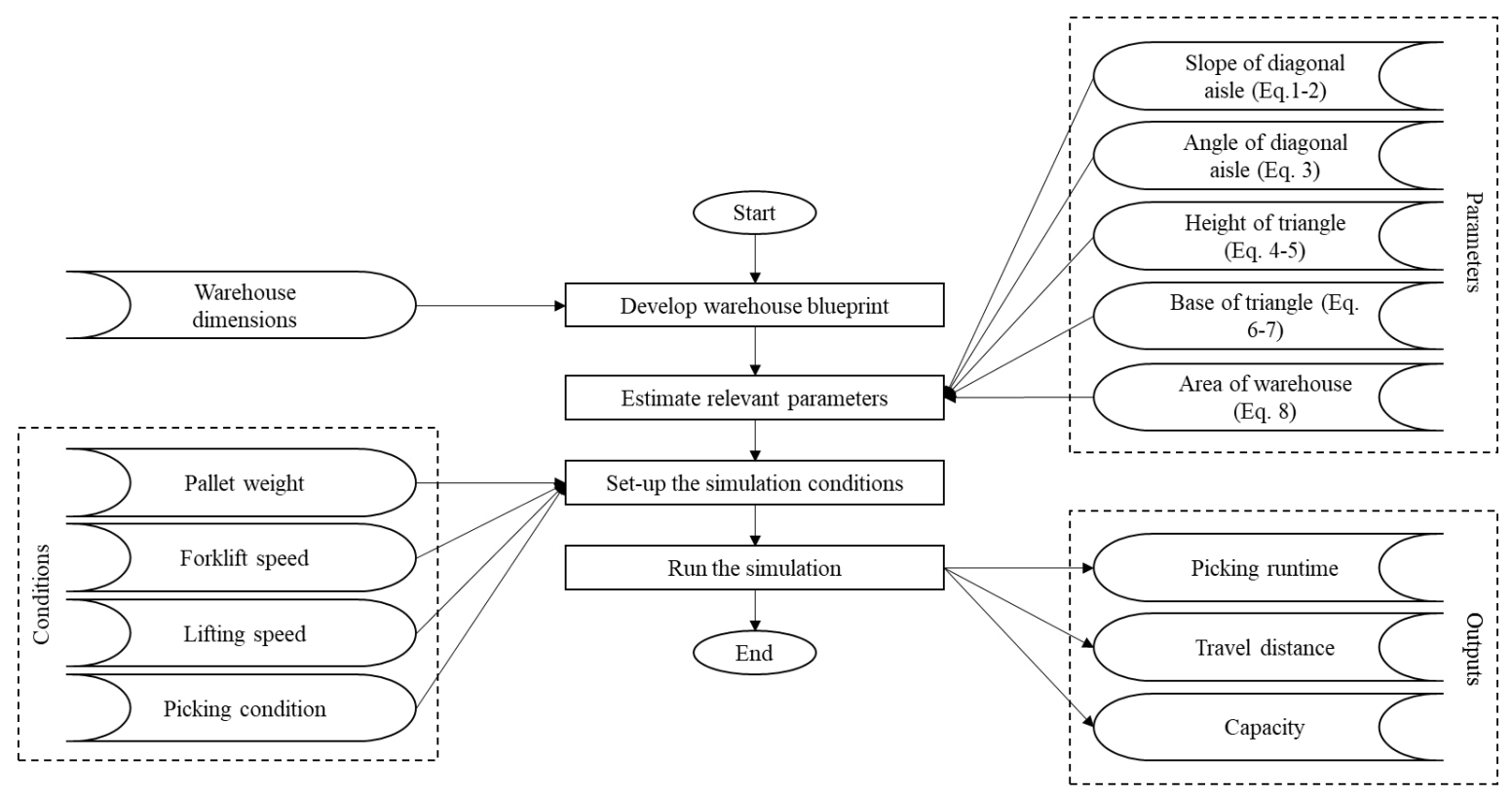

Fig. 5. Heuristic comparative assessment of UW designs (HCAUD) framework

\section{CASE STUDY: SHEMBERG MAR- KETING CORPORATION}

\subsection{Plant Linearisation Program (PLP)}

A Philippine carrageenan manufacturing company, Shemberg Marketing Corporation, intends to implement a Plant Linearisation Program (PLP), wherein a re-layout of the entire plant would be conducted. The scope of the PLP involves the re-design of individual production, warehousing, and other facilities.

In line with this, the company's Blending Area, Magnetising Area, and Primary Blended Powder Warehouse (PBPW) are proposed to be situated in one building, as presented in Fig. 6. The Blending Area requires a space allocation for its accessories, mainly comprised of chemicals and powder ingredients.

The blenders would require a maximum of 20 tons or 20 pallets worth of accessories each. In the proposed linearisation layout, there is no space allocation for the accessories. The management intends to reduce the PBPW to utilise more space for the Blending Area.

Despite the possible reduction in space, the PBPW has to be re-designed so that travel distances from the P\&D point and picking run-times are kept at a minimum while maximising warehouse capacity.
In line with these objectives, this study incorporates the Flying-V and Fishbone design.

\subsection{DESIGN SPECIFICS}

Zooming into the PBPW in the initial design of the PLP, the specific dimensions of the conventional design are presented in Fig. 7. For the capacity improvement, the initial design of the PBPW in the PLP is modified to propose an alternative layout. The said design is much like the conventional design, but with $\mathrm{a}_{\mathrm{p}}=2.7$ metres. Furthermore, the Flying- $\mathrm{V}$ and Fishbone design of the PBPW is presented in Figs. 8 and 9 , respectively.

\section{SIMULATION RESULTS}

Based on the design specifics provided in Figs. 6 to 9 , each UW design's parameter and design feature was computed using Equations (1) through (8). The results are presented in Table 2 . The Flying- $\mathrm{V}$ and Fishbone designs occupy relatively less space than conventional designs (e.g., initial PLP design, alternative PLP design). With this, the Flying-V and Fishbone designs exhibit $7.5 \%$ and $5.0 \%$ more capacity than the conventional designs. The calculated parameters and features and the specific designs for the UW designs assessed in this study were entered into the FlexSim software for running the simulation. The results of the simulation are presented in the following discussion. 


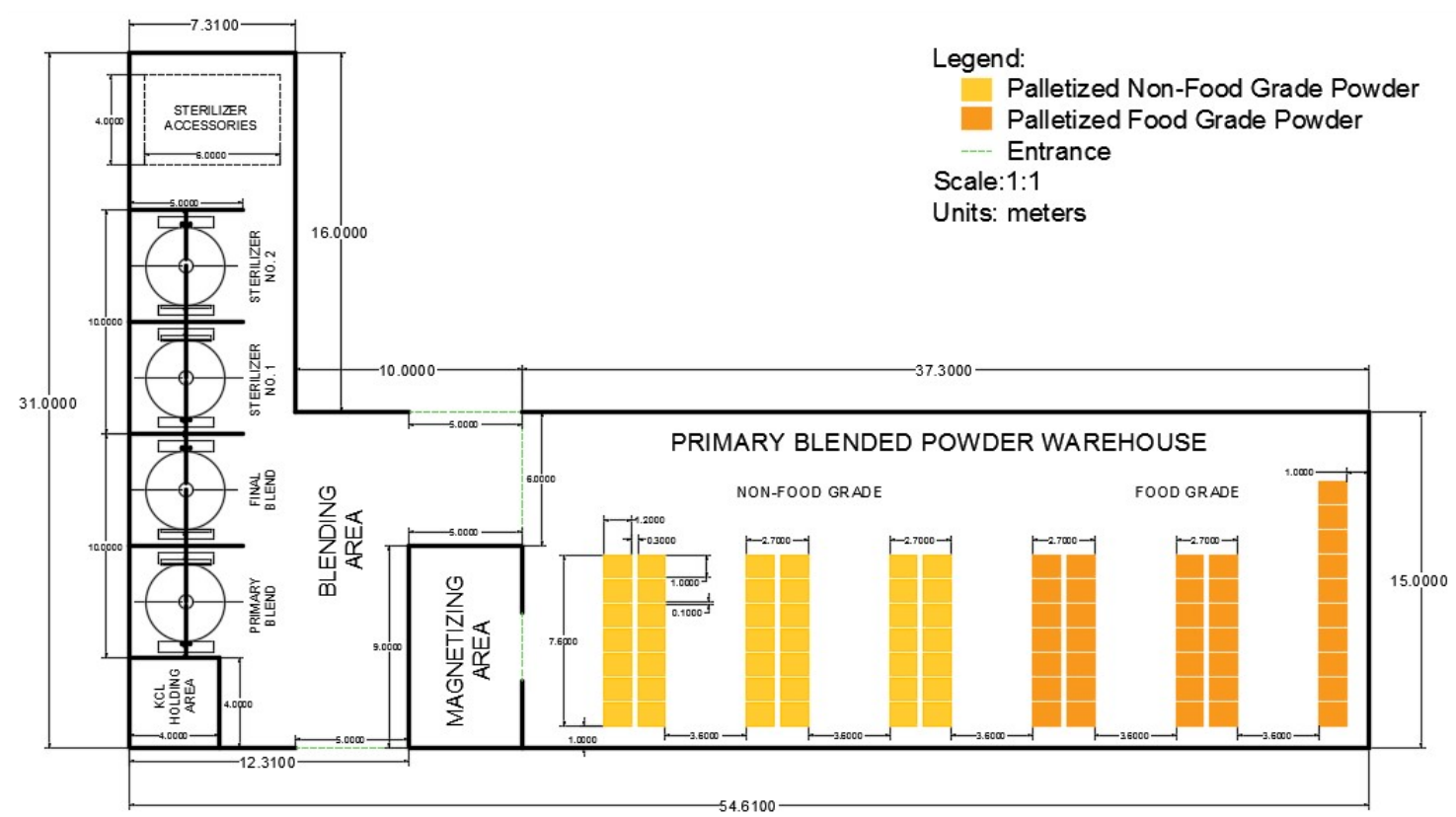

Fig. 6. Initial design based on the PLP

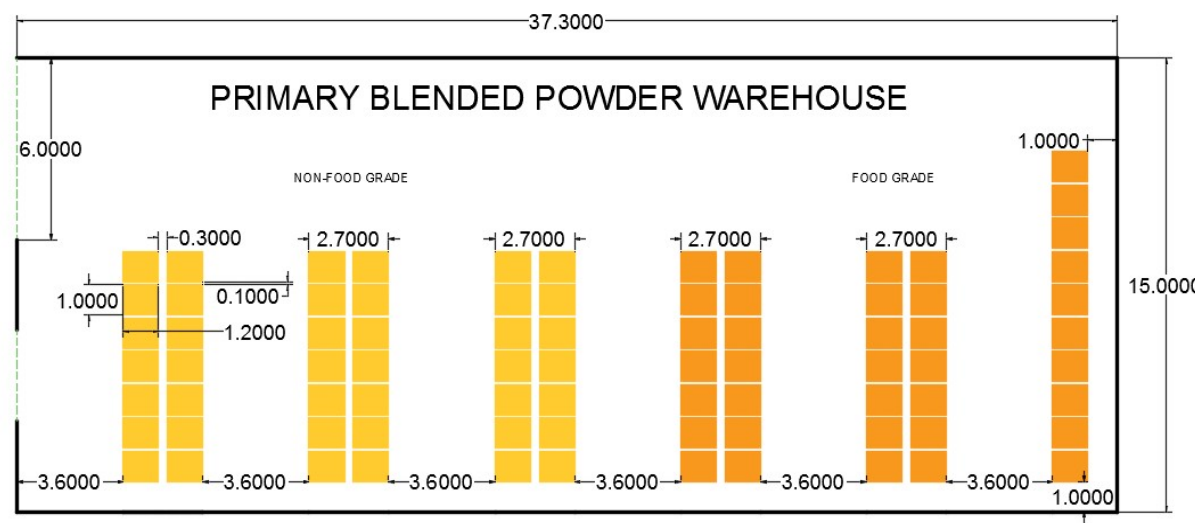

Legend:

Palletized Non-Food Grade Powder

Palletized Food Grade Powder - Entrance/Exit Point

Fig. 7. Conventional design of the PBPW

Scale: $1: 1$

Units: meters

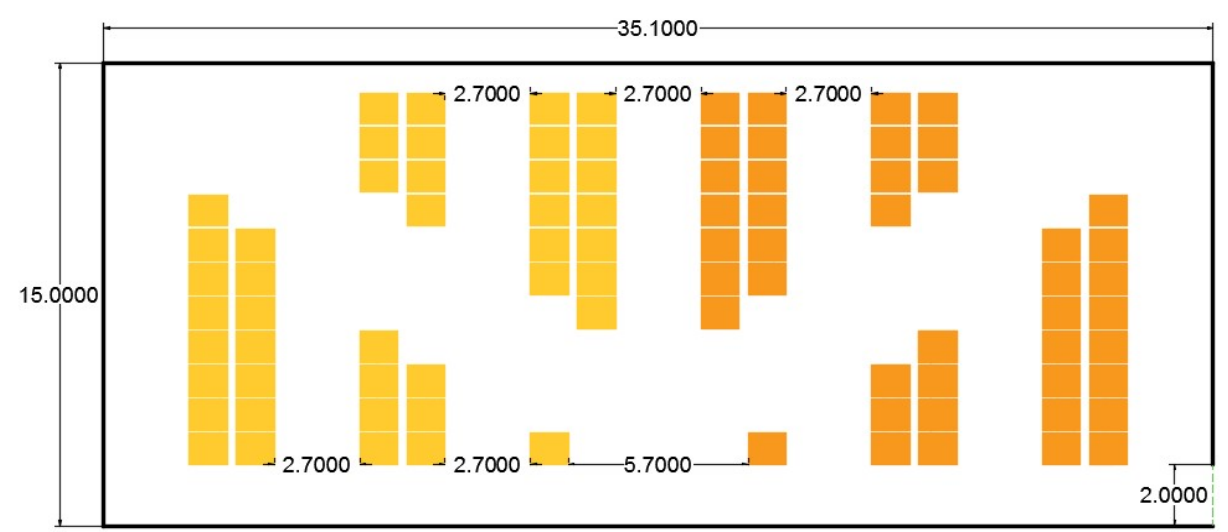

Legend:

Palletized Non-Food Grade Powder

Palletized Food Grade Powder

Fig. 8. Flying-V design of the PBPW

Scale:1:1

Units: meters 


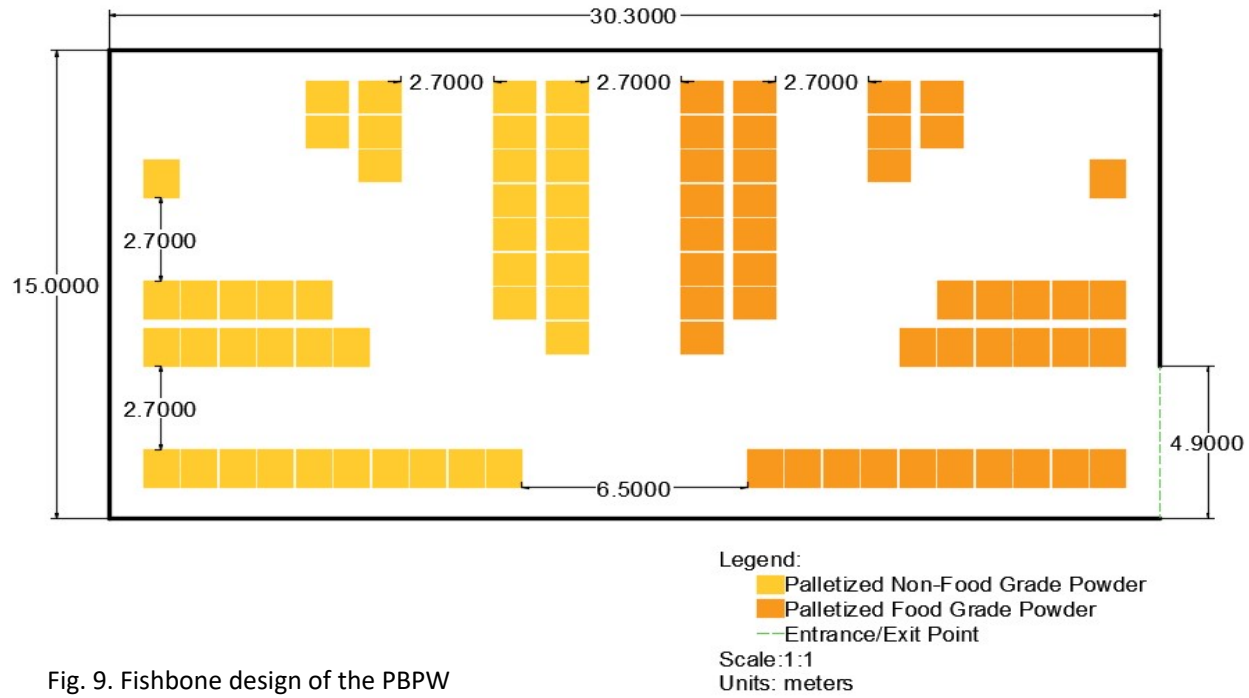

Tab. 2. Calculated parameters and features

\begin{tabular}{|c|c|c|c|c|c|}
\hline PARAMETERS & UNIT & INITIAL PLP DESIGN & $\begin{array}{c}\text { ALTERNATIVE PLP } \\
\text { DESIGN }\end{array}$ & FLYING-V DESIGN & FISHBONE DESIGN \\
\hline$e_{w}$ & metres & 1.00 & 1.00 & 1.00 & 1.00 \\
\hline$e_{l}$ & metres & 1.20 & 1.20 & 1.20 & 1.20 \\
\hline$e_{h}$ & metres & 1.00 & 1.00 & 1.00 & 1.00 \\
\hline$u$ & metres & - & - & 4.30 & 2.00 \\
\hline$a_{1}$ & metres & 0.10 & 0.10 & 0.10 & 0.10 \\
\hline$a_{2}$ & metres & 0.30 & 0.30 & 0.30 & 0.30 \\
\hline$a_{3}$ & metres & 1.00 & 1.00 & 1.00 & 1.00 \\
\hline$a_{c}$ & metres & - & - & 2.85 & 3.50 \\
\hline$a_{p}$ & metres & 3.60 & 2.70 & 2.70 & 2.70 \\
\hline \multicolumn{6}{|l|}{ FEATURES } \\
\hline$m$ & metres & - & - & 0.94 & 89.00 \\
\hline$\theta$ & degrees & - & - & 43.00 & 42.00 \\
\hline$\beta$ & metres & - & - & 15.00 & 15.00 \\
\hline$\propto$ & metres & - & - & 17.55 & 15.15 \\
\hline$A$ & metres & 37.30 & 37.30 & 35.10 & 30.30 \\
\hline$B$ & metres & 15.00 & 15.00 & 15.00 & 15.00 \\
\hline Area & square metres & 559.50 & 559.50 & 526.50 & 454.50 \\
\hline Capacity & pallets & 80.00 & 80.00 & 86.00 & 84.00 \\
\hline
\end{tabular}

The simulation results revealed that the Fishbone design consistently outperformed the Flying-V, initial PLP, and alternative PLP designs in terms of picking run-time. Moreover, the disparity of the results also tended to diverge as the number of random picks increased, which made the advantage of the Fishbone design more elaborate. While less advantageous than the Fishbone design, the Flying-V design was relatively superior to the conventional designs in picking run-time. The comparison of picking run-time of the UW design assessed in this study is presented in Figure 10. The results reveal the following ranking in terms of picking run time: Fishbone design $>$ Flying-
V design $>$ alternative PLP design $>$ initial PLP design.

The simulation results also revealed that the Fishbone design consistently outperformed the other UW designs assessed in this study in terms of travel distance. Interestingly, the Flying- $\mathrm{V}$ design seemed to fail at this performance indicator by an overwhelming extent compared to other UW designs. The alternative PLP design, on the other hand, appeared to have relatively the same results as the initial PLP design. A comparison of the UW designs' travel distance over the different picks is presented in Fig. 11. In general, the results reveal the following ranking in 


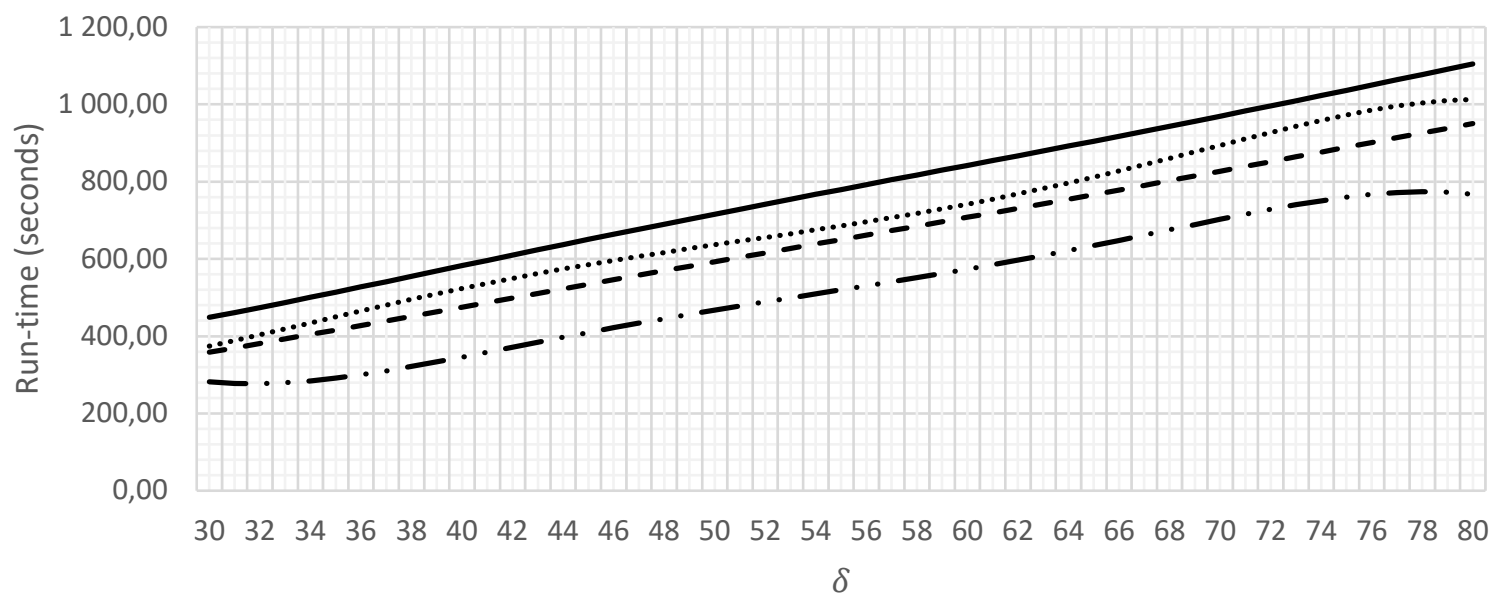

Initial PLP Design Alternative PLP Design

- - - Flying-V Design - Fishbone Design

Fig. 10. Comparison of picking run-time

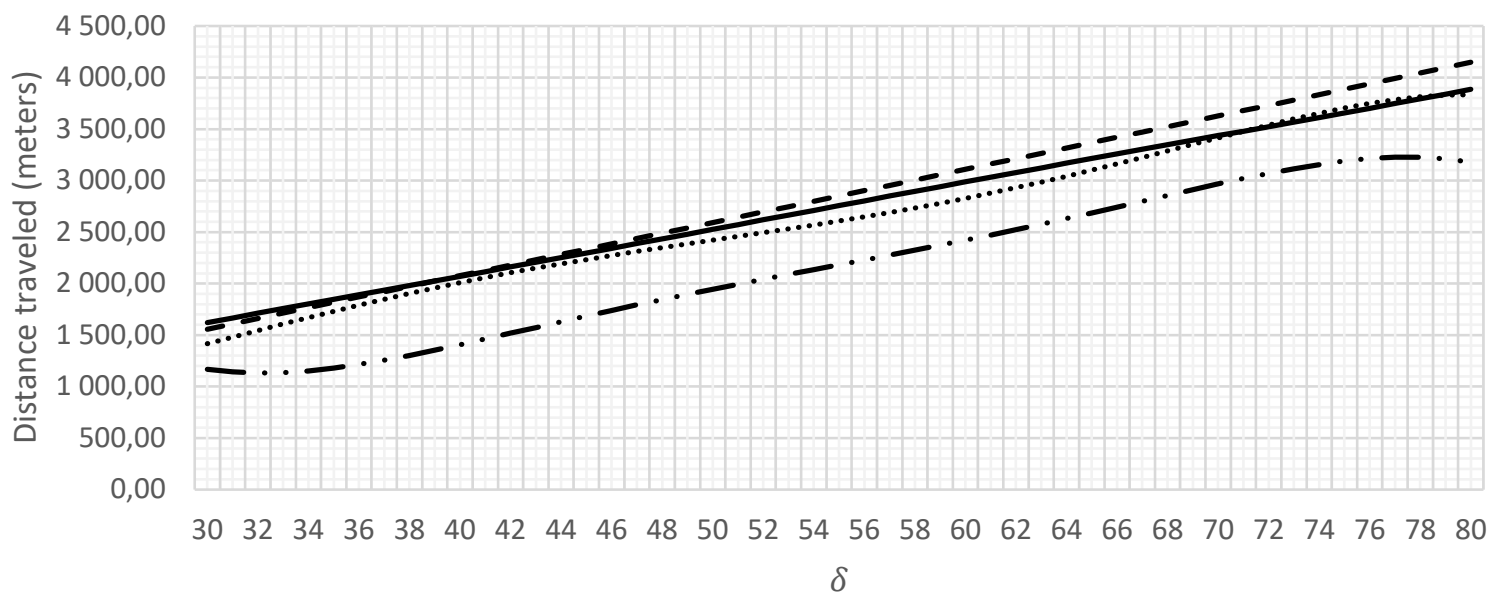

— Initial PLP Design ........ Alternative PLP Design - - - Flying-V Design — - Fishbone Design

Fig. 11. Comparison of travel distance

terms of travel distance: Fishbone design $>$ alternative PLP design $>$ initial PLP design $>$ Flying-V design.

\section{DISCUSSION}

Considering the initial PLP design as a reference point, in terms of picking run-time, as illustrated in Fig. 12, the per cent improvement of the Fishbone design, when compared to the other UW designs, is overwhelmingly large. The literature has always emphasised significant improvements with the Fishbone design in terms of travel distance (Pohl et al., 2011; Cardona et al., 2012; Dukic \& Opetuk, 2012; Clark \& Meller, 2013; Çelik \& Süral, 2014; Cardona et al., 2015). However, no research produced the same results in terms of picking run-time, which is an equally important performance indicator if not more critical. This study provides the first insights on the performance of both conventional and non-conventional UW designs in terms of this metric. It is also worth noting that, while the Flying-V design presents more improvement than the alternative PLP design, the advantage is relatively insignificant because their functions are relatively close to each other. Furthermore, for all UW design, per cent improvement in terms of picking run-time seems to decrease as the number of random picks increases. In the case of the Fishbone design, while per cent improvement generally projects a downtrend together with the number of random picks, its function seems to fluctuate. The 
main implication of this observed behaviour lies in optimal random picks to allow that the maximised per cent improvement for the Fishbone design. In this study, 34-36 random picks seem to produce maximum utility for the Fishbone design.

Similar findings for the Fishbone design can be inferred in terms of per cent improvement for the travel distance. However, interestingly, the Flying- $\mathrm{V}$ design seems to exhibit unproductive results in this performance indicator. As illustrated in Fig. 13, the Flying-V design consistently fails to improve the initial PLP design. According to Feng et al. (2018), for the Flying- $\mathrm{V}$ design to exhibit improvement to the conventional design, it usually "sacrifices some space". Based on their analytical evaluations, they suggested that "if the warehouse is large enough, then Flying-V is a better choice"; however, "if the warehouse is a small size, the conventional aisle configuration is more suitable". Thus, in this case, the Flying-V design may have been unsuitable because of the warehouse's limited space. In this case, the conventional UW designs are preferred to the Flying- $\mathrm{V}$ design.

Furthermore, this study confirms the findings of previous studies that attempted to compare the Flying- $\mathrm{V}$ and the Fishbone design. Gue et al. (2012) emphasised that "the Fishbone design is generally preferred to the Flying-V", which can also be suggested based on this study's findings. In general, in terms of capacity, picking run-time, and travel distance, the Fishbone design is deemed the most advantageous design compared to the Flying- $\mathrm{V}$, alternative PLP, and initial PLP designs.

The findings of this study suggest that among the UW designs considered for improving the PBPW as part of the PLP in the case firm, the proposed Fishbone design is most suitable. The final proposed

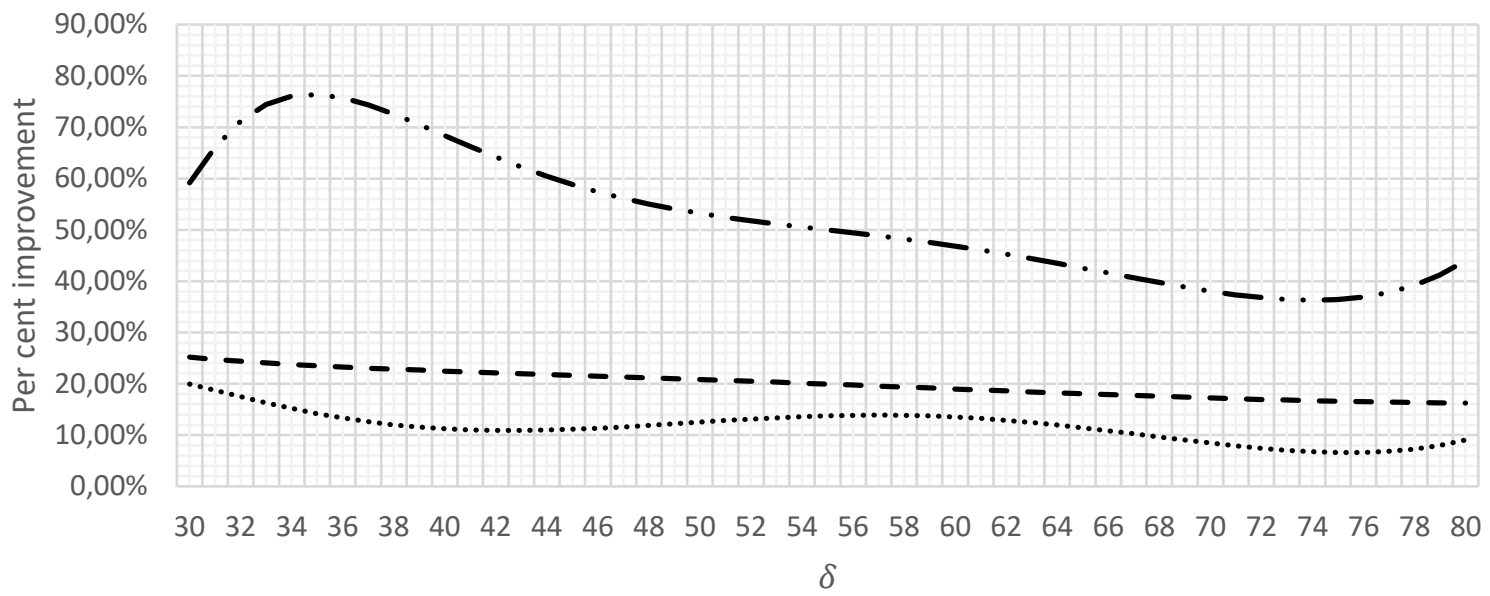

….... Alternative PLP Design $\quad$ _ - - Flying-V Design _ _ - Fishbone Design

Fig. 12. Improvement in picking run-time

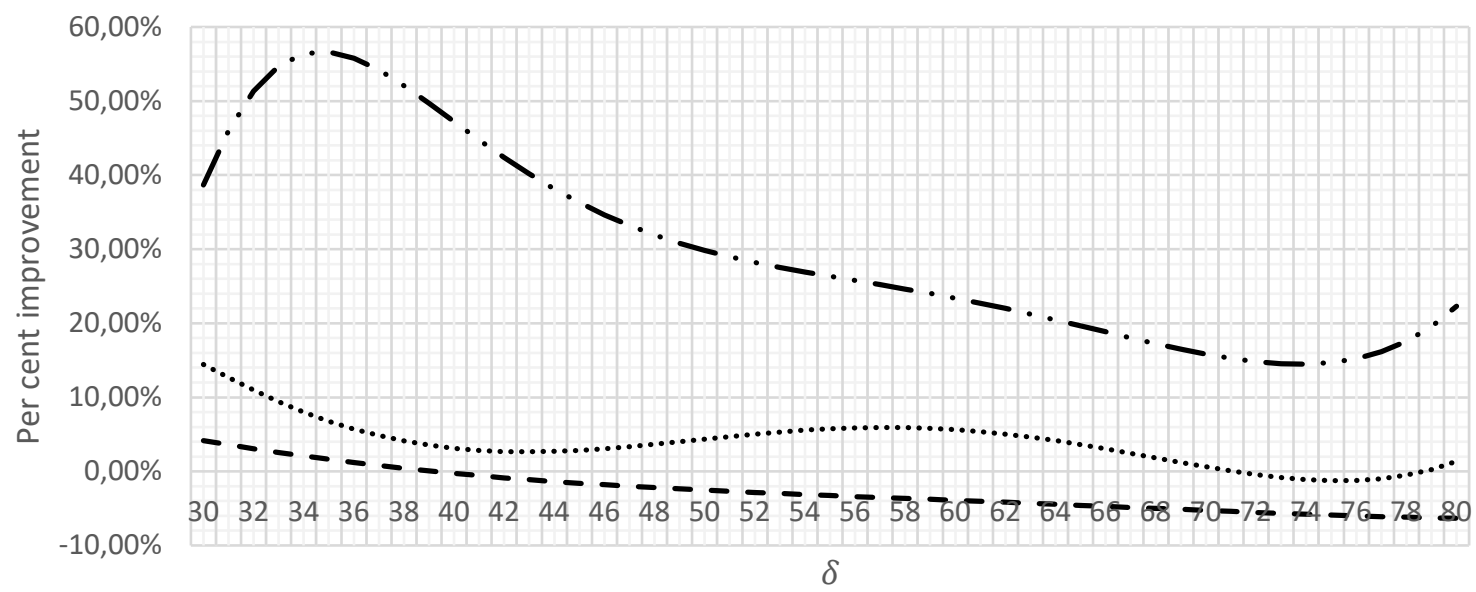




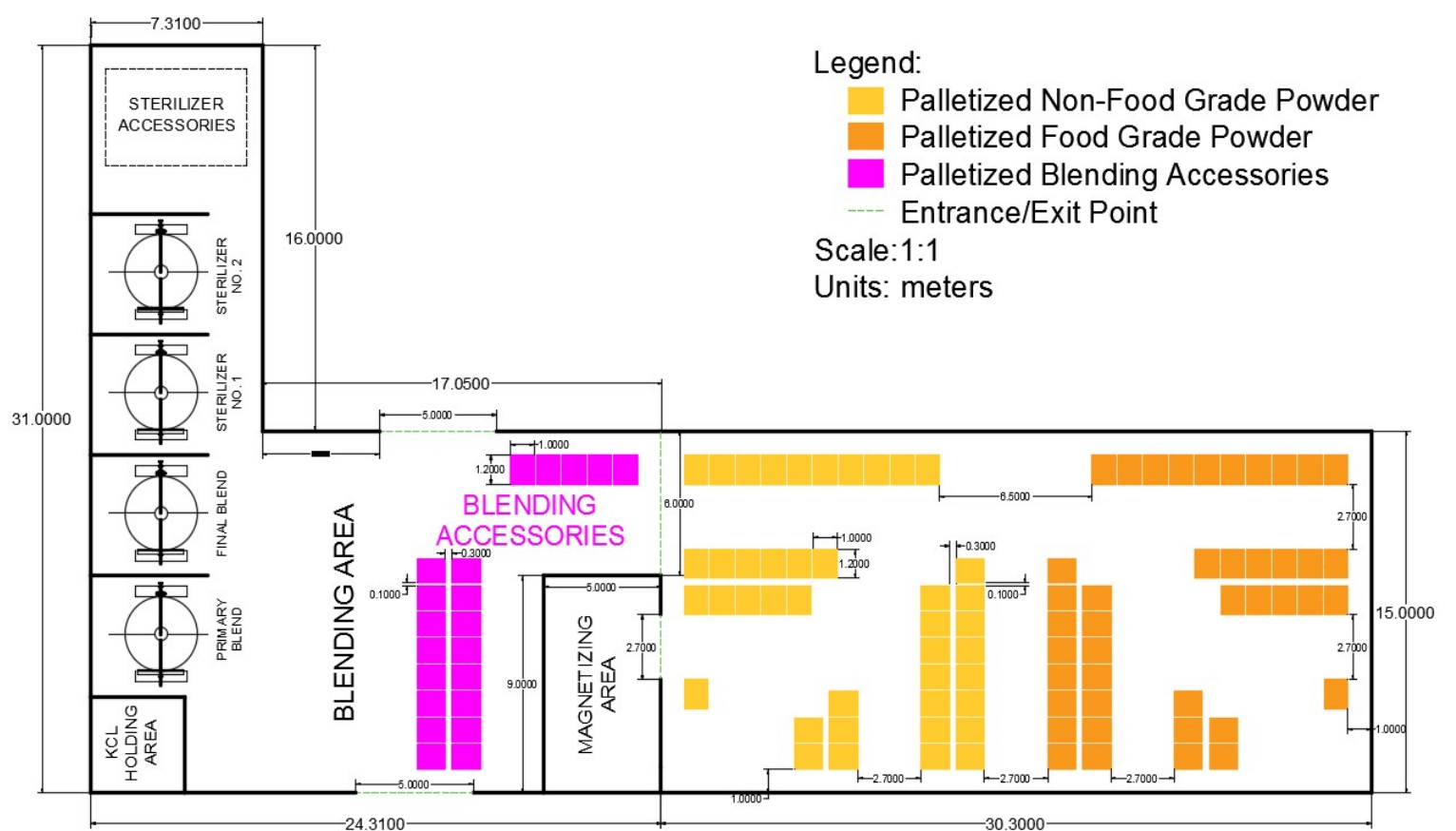

Fig. 14. Final proposed design integrating the Fishbone design in the PLP

design associated with the findings is presented in Fig. 14. With the proposed design, the company is expected to save, on average, $52.39 \%$ of picking runtime, $32.25 \%$ travel distance, and increase storage capacity by $7.5 \%$. For future warehouse improvement projects, the framework developed in this study (HCAUD framework) can also be adopted. Compared to other approaches the developed framework, is more convenient and less complicated by a significant degree but produces relatively the same results. Thus, it can be easily replicated by industry practitioners for in-house warehouse assessments. The attempt to measuring picking run-time, which was successfully demonstrated in this study, expands the dimensions for evaluating warehouse designs. Thus, in selecting future UW design options, picking runtime may now be considered, which offers a more systematic approach for UW design selection. The study findings also demonstrate that while the Flying$\mathrm{V}$ design was developed as an improvement of the conventional designs (Gue \& Meller, 2009a), its application is limited by various factors such as warehouse space availability. In relatively small warehouses, similar to the warehouse under investigation of this work, a transition from conventional design to the Flying- $\mathrm{V}$ design may not be adequate.

\section{CONCLUSIONS}

The UW design approaches are continuously expanding with the improvements in systems analysis and decision-aiding tools. These potentially enhance the capacity of managers to develop, assess, and select UW designs, especially in the manufacturing sector. Among the first attempts in the literature explored in this article were (1) the development of a novel approach to a heuristic comparative assessment of non-conventional UW designs, (2) assessment of UW design in the context of a real-case scenario, and (3) the measurement of picking run-time as a performance indicator for assessing UW designs. The Flying- $\mathrm{V}$ and Fishbone designs were among the UW designs explored in this article. This work developed a framework based on the FlexSim software package for the convenient analysis of UW designs. The results suggest that the Fishbone design provides the most advantage compared to the Flying- $\mathrm{V}$ and the other conventional designs. The findings also supported previous literature that suggested limitations on the Flying- $\mathrm{V}$ design, implying that the Flying- $\mathrm{V}$ design may have been an unsuitable option due to the limited space of the warehouse. Based on the findings, a proposed UW design for the PLP was developed, integrating the Fishbone design. The company is expected to save, on average, $52.39 \%$ of picking runtime, $32.25 \%$ travel distance, and increase storage capacity by $7.5 \%$ with the proposed design. Furthermore, industry practitioners can quickly adopt the developed HCAUD framework for their in-house UW design assessments.

While this work considers multiple performance indicators for the UW design assessment, their inte- 
gration in outranking the UW designs was not explicitly applied, which would have been a more systematic approach to outranking the alternatives. In this regard, for future research, a multi-attribute decision-making approach may be employed to address this gap. Furthermore, since this research case environment limits the Flying- $\mathrm{V}$ design's applicability, its comparison with the Fishbone design may be biased. Thus, future studies could replicate the procedures through the proposed framework in a more suitable setting, i.e., a relatively larger warehouse. Lastly, while several performance indicators have been identified in previous research, only several (three) performance indicators were measured in this study. Thus, it may be relevant to consider multiple performance indicators in the assessment of UW design while employing the framework proposed in this work.

\section{LITERATURE}

Berry, J. R. (1968). Elements of warehouse layout. International Journal of Production Research, 7(2), 105-121. doi: 10.1080/00207546808929801

Cardona, L. F., Rivera, L., \& Martínez, H. J. (2012). Analytical study of the Fishbone warehouse layout. International Journal of Logistics Research and Applications, 15(6), 365-388. doi: 10.1080/13675567.2012.743981

Cardona, L. F., Soto D. F., Rivera, L., \& Martínez, H. J. (2015). Detailed design of fishbone warehouse layouts with vertical travel. International Journal of Production Economics, 170, 825-837. doi: 10.1016/j. ijpe.2015.03.006

Çelik, M., \& Süral, H. (2014). Order picking under random and turnover-based storage policies in fishbone aisle warehouses. IIE Transactions, 46(3), 283-300. doi: 10.1080/0740817X.2013.768871

Clark, K. A., \& Meller, R. D. (2013). Incorporating vertical travel into non-traditional cross aisles for unit-load warehouse designs. IIE Transactions, 45(12), 13221331. doi: 10.1080/0740817X.2012.724188

Dukic, G., \& Opetuk, T. (2012). Warehouse layouts. In R. Manzini (Ed.), Warehousing in the Global Supply Chain (pp. 55-69). London, UK: Springer. doi: 10.1007/978-1-4471-2274-6

Feng, L., Qi, M., Hua, S., \& Zhou, Q. (2018). Picking station location in traditional and flying-v aisle warehouses for robotic mobile fulfilment system. In 2018 IEEE International Conference on Industrial Engineering and Engineering Management (IEEM) (pp. 14361440). IEEE. doi: 10.1109/IEEM.2018.8607301

Francis, R. L. (1967a). On some problems of rectangular warehouse design and layout. Journal of Industrial Engineering, 18(10), 595-604.

Francis, R. L. (1967b). Sufficient conditions for some optimum-property facility designs. Operations Research, 15(3), 448-466.

Glock, C. H., \& Grosse, E. H. (2012). Storage policies and order picking strategies in U-shaped order-picking systems with a movable base. International Journal of Production Research, 50(16), 4344-4357. doi: 10.1080/00207543.2011.588621

Gue, K. R., \& Meller, R. D. (2009). Aisle configurations for unit-load warehouses. IIE Transactions, 41(3), 171182. doi: $10.1080 / 07408170802112726$

Gue, K. R., Ivanović, G., \& Meller, R. D. (2012). A unit-load warehouse with multiple pickup and deposit points and non-traditional aisles. Transportation Research Part E: Logistics and Transportation Review, 48(4), 795-806. doi: 10.1016/j.tre.2012.01.002

Huihui, S., Xiaoxia, M., \& Xiangguo, M. (2016). Simulation and optimization of warehouse operation based on Flexsim. Journal of Applied Science and Engineering Innovation, 3(4), 125-128.

Kęsek, M., Adamczyk, A., \& Klaś, M. (2018). Computer simulation of the operation of a longwall complex using the "Process Flow" concept of FlexSim software. In International Conference on Intelligent Systems in Production Engineering and Maintenance (pp. 97-106). Cham, UK: Springer.

Kocaman, Y., Öztürkoğlu, Ö., \& Gümüşoğlu, Ş. (2021). Aisle designs in unit-load warehouses with different flow policies of multiple pickup and deposit points. Central European Journal of Operations Research, 29, 323-355. doi: 10.1007/s10100-019-00646-9

Liu, T., Duan, Y., \& Liu, Y. (2016). Simulation and optimization of the AS/RS based on Flexsim. In J. Hung, N. Yen, \& K. C. Li (Eds.), Frontier computing (pp. 855863). Lecture Notes in Electrical Engineering, 375. Springer. doi: 10.1007/978-981-10-0539-8_84

Masae, M., Glock, C. H., \& Grosse, E. H. (2020a). Order picker routing in warehouses: A systematic literature review. International Journal of Production Economics, 224, 107564. doi: 10.1016/j.ijpe.2019.107564

Masae, M., Glock, C. H., \& Vichitkunakorn, P. (2020b). Optimal order picker routing in the chevron warehouse. IISE Transactions, 52(6), 665-687. doi: 10.1080/24725854.2019.1660833

Masae, M., Vichitkunakorn, P., \& Glock, C. H. (2019). Optimal routing of order pickers in the leaf warehouse. In The 24th International Symposium on Logistics (ISL 2019), Würzburg, Germany.

Meller, R. D., \& Gue, K. R. (2009). The application of new aisle designs for unit-load warehouses. In Proceedings of 2009 NSF Engineering Research and Innovation Conference, Honolulu, Hawaii.

Moder, J. J., \& Thornton, H. M. (1965). Quantitative analysis of factors affecting floorspace utilization of palletized storage. Journal of Industrial Engineering, 16(1), 8-18.

Öztürkoğlu, Ö. (2016). Effects of varying input and output points on new aisle designs in warehouses. In 2016 IEEE Congress on Evolutionary Computation (CEC) (pp. 3925-3932). IEEE. doi: 10.1109/ CEC.2016.7744287

Öztürkoğlu, Ö., \& Hoser, D. (2019). A discrete cross aisle design model for order-picking warehouses. European Journal of Operational Research, 275(2), 411-430. doi: 10.1016/j.ejor.2018.11.037

Öztürkoğlu, O., Gue, K. R., \& Meller, R. D. (2012). Optimal unit load warehouse designs for single-command operations. IIE Transactions, 44(6), 459-475. doi: 10.1080/0740817X.2011.636793

Pohl, L. M., Meller, R. D., \& Gue, K. R. (2009a). Optimizing fishbone aisles for dual-command operations in 
a warehouse. Naval Research Logistics, 56(5), 389403. doi: 10.1002/nav.20355

Pohl, L. M., Meller, R. D., \& Gue, K. R. (2009b). An analysis of dual-command operations in common warehouse designs. Transportation Research Part E: Logistics and Transportation Review, 45(3), 367-379. doi: 10.1016/j.tre.2008.09.010

Pohl, L. M., Meller, R. D., \& Gue, K. R. (2011). Turnoverbased storage in non-traditional unit-load warehouse designs. IIE Transactions, 43(10), 703-720. doi: 10.1080/0740817X.2010.549098

Tang, X. Y., Yang, L. L., Zhang, J. J., Shi, J., \& Chen, L. C. (2013). Research on AS/RS simulation based on Flexsim. Applied Mechanics and Materials, 347-350, 406-410. doi: 10.4028/www.scientific.net/amm.347350.406

Venkitasubramony, R., \& Adil, G. K. (2016). Analytical models for pick distances in fishbone warehouse based on exact distance contour. International Journal of Production Research, 54(14), 4305-4326. doi: 10.1080/00207543.2016.1148277

White, J. A. (1972). Optimum design of warehouses having radial aisles ${ }^{1}$. AIIE Transactions, 4(4), 333-336. doi: 10.1080/05695557208974871

Yafei, L., Qingming, W., \& Peng, G. (2018, March). Research on simulation and optimization of warehouse logistics based on flexsim-take $\mathrm{C}$ company as an example. In 2018 7th International Conference on Industrial Technology and Management (ICITM) (pp. 288-293). IEEE. doi: 10.1109/ICITM.2018.8333963 